\title{
Cultural Sensitivity of Polish, Ukrainian and Belarusian Students
}

\begin{abstract}
The aim of the study was to establish the level of cultural sensitivity of Polish, Ukrainian and Belarusian students, as well as characterize the differences in this respect between these groups. Cultural sensitivity is understood here as an indicator of intercultural communicative ability, which manifests itself in willingness to engage in interactions with people of different cultures.

The study was conducted using a diagnostic poll with the research tool Intercultural Sensitivity Scale developed by G.M Chen and J.W. Starosta. Another methods employed included the analysis of variance (ANOVA) and LSD test. The subjects of the study were 293 students of Maria Curie-Skłodowska University and Vincent Pol University in Lublin, 91 of whom were Polish, the same number of Ukrainians and 101 Belarusians.

The research showed that the Ukrainian students are the most willing to engage in conversation with a person of different culture, obtaining average and high results for all factors. The lowest results, in turn, belong to the Poles, whose results were all average. Statistical analyses showed that the differences are statistically significant for 4 out of 5 examined dimensions of sensitivity. The students from Ukraine turned out to be the most diversifying group.
\end{abstract}

\section{Keywords:}

intercultural education, intercultural communication competence, cultural sensitivity, people of foreign culture, students

1 Institute of Pedagogy/ Department of Intercultural Education, Faculty of Pedagogy and Psychology, Maria Curie-Skłodowska University in Lublin, Poland, e-MaIL: mariusz.korczynski@ poczta.umcs.lublin.pl.

2 Department of Special Pedagogy, Faculty of Health Sciences, Vincent Pol University in Lublin, Poland, E-MAIL: mateuszstefanek@wssp.edu.pl. 


\section{INTRODUCTION}

The term cultural sensitivity appears in the literature mostly in the context of interactions taking place in multicultural environments. It is seen as an element of intercultural communicative competence. Different scholars, however, provide various definitions of it. According to K.T. Konecki and P. Chomczyński (2012), the term, if approached from the perspective of interactions taking place in a multicultural society, can be explained as the ability to perceive and understand multiple aspects of social relations, the ability to take multiple points of view, compare and develop ideas. A. Reber (2000, p. 835), in turn, in his Dictionary of Psychology says that "the ability to recognize the feelings of other people, [...] in this understanding is connected with empathy", which in a multicultural environment relies on the ability to "understand another human being in his or her cultural environment, when we try to get into his or her spirit, at the same time trying to understand his or her situation” (Śliwerski, 2015, p. 515). Yet another definition was suggested by D. Cieślikowska (2006), who saw cultural sensitivity as the awareness of cultural differences and the ability to interpret them in various situations. It is, therefore, a means of shaping the constructive reality and the future.

The forefather of the term, however, is M. Bennett (1993). He treated the development of cultural sensitivity as the ability to modify one's attitude not only emotionally but also cognitively and behaviorally, when an individual moves from the stage of negation to integration in the process of the development of competence. In other words, culturally sensitive people are able to reach the state of double identity and incorporate cultural differences through gradual overcoming or concealing the problems of negation. The development of sensitivity involves constant education on various cultures and acquiring the ability to deal with them. Bennett assumed a model of the development of cultural sensitivity that describes different reactions of the people who encounter cultural differences. It consists of 6 stages characterized by increasing cultural sensitivity. It specifies the basic cognitive orientations adopted by people to understand cultural differences. Each stage comprises more and more elaborate differences, which makes it possible to experience increasing distinctness of cultures. The first 3 stages deal with ethnocentrism and show how the culture of an individual is perceived and placed at the center of reality. The 3 latter stages are ethnorelativist in character, which means that a culture starts to be accepted and positive behavior and values begin to be drawn from it (Bennett, 1993). An increase in cultural sensitivity happens as a result of the development of attitudes such as understanding, open-mindedness, lack of prejudice, all of which evolve to create the path of an individual's development. 
An important piece of research that fits into this conception was carried out by the scholars from the Department of Pedagogy and Psychology of the University of Białystok. One of the factors influencing the intercultural communicative competence of the young people who were the subject of the study was cultural sensitivity as understood above (Nikitorowicz et al., 2013).

A slightly different approach to this issue is represented by G.M. Chen and J.W. Starosta (1997). They assumed that cultural sensitivity is related to cognitive, affective and behavioral aspects of interactive situations and is inseparably connected with emotions. Taking this into account, they defined cultural sensitivity as the ability of a person to develop positive emotions towards understanding and appreciation of cultural differences which induce proper and efficient behavior in intercultural communication. Cultural sensitivity was, therefore, seen as a dynamic concept according to which culturally sensitive people should be willing to motivate themselves to understand, appreciate and accept cultural differences as well as strive to achieve positive results of intercultural relations. When developing their model, Chen and Starosta referred to the metaphor of umbrella, which combines three abilities: cognitive, affective, and behavioral. The effect of such approach is a model of intercultural communicative competence consisting of three aspects: cultural awareness, sensitivity and ability. Cultural sensitivity was of the highest importance as they assumed that in a globalized, multicultural society the aspect that refers to emotional desire of a person to confirm, appreciate and accept cultural differences via contact must be crucial. They also acknowledged the fact that such positive emotional reactions lead to the recognition and respect of cultural differences (Fritz et al., 2015). Such view of cultural sensitivity has become the basis of the study presented below.

\section{METHODOLOGY}

The object of the presented study was the cultural sensitivity, that is, emotional readiness to engage in a dialogue with a person of different culture, of Polish, Ukrainian and Belarusian students. Our aim was to establish the level of cultural sensitivity of these groups and determine the differences between them.

The research problem was formulated in the form of the following questions: Are there any differences in the levels of cultural sensitivity of Polish, Ukrainian and Belarusian students? If there are, how can they be characterized?

The adopted dependent variable is cultural sensitivity in the form of its dimensions. The independent variable is the nationality of the subjects. 
It had been assumed that the students from Ukraine and Belarus present higher levels of cultural sensitivity. The reason was their decision to study in a different country, which must have been made with the awareness of the necessity to interact, communicate and negotiate cultural patterns with people of different cultures. As a result, such students should be more motivated to understand, appreciate and accept cultural differences than the Polish students, which, in turn, should make them more willing to engage in communication with people of different cultures (cf. Korczyński \& Świdzińska, 2017).

Being aware of the existence of a number of confounding variables, we focused only on the analysis of the differences stemming from the subjects' nationalities. We assumed that ethnical and cultural awareness is the most important factor determining the level of cultural sensitivity. The analyses, similarly to the main hypothesis, take into account the fact that the studies were conducted in Poland rather than Belarus or Ukraine.

The research is located in the objectivist paradigm thanks to the method of diagnostic poll with the questionnaire technique. The research tool used to measure cultural sensitivity was Intercultural Sensitivity Scale developed by G.M. Chen and W.J. Starosta (1997). It consists of 24 statements allowing to assess five dimensions of cultural sensitivity (Interaction Engagement, Respect for Cultural Differences, Interaction Confidence, Interaction Enjoyment, and Interaction Attentiveness). One out of five answers provided by the Likert scale was given to each statement. The answers range from "Strongly agree" to "Strongly disagree". The procedure adopted by the authors involves a coding key that allows to establish three ranges of results, namely high, average and low. Such scale has only been used in Germany and the USA (Fritz, Mollenberg, \& Chen, 2002). The scientists from the Department of Intercultural Education at the Faculty of Education and Psychology at Maria Curie-Skłodowska University have made an attempt at adapting this tool for the specific conditions of Eastern Europe. The present study is, therefore, a pioneering piece of cultural sensitivity research according to the conception of G.M. Chen and W.J. Starosta in this part of the world.

The study was conducted at Maria Curie-Skłodowska University and Vincent Pol University in Lublin from May to June 2016. Both universities are leading in terms of internationality. At the time when the study was being conducted, 1600 and 719 students were studying at both universities, respectively. Maria CurieSkłodowska University is currently holding the position of the most international university in Poland with the rate of $6.72 \%$. It is also the leader among public universities in terms of the number of Ukrainian students. Vincent Pol University, in turn, is 29th in the country (10th among private universities) in terms of the 
absolute number of foreign students. When it comes to the category of internationality, however, due to the total number of students amounting to 1689, VPU is one of the best in Poland with the rate of 42.57\% (Siwińska, 2017).

Both universities are, therefore, places where interactions do not arise due to territorial proximity but thanks to "[...] the will to acquaint, understand and engage in dialogue, the desire to interact despite differences, possibly even thanks to them" (Nikitorowicz, 2014, p. 181). The process of interpersonal communication takes place in a continuum "[...] from monologue to the dialogue of cultures, from the dominance of stereotypes and prejudice to mutual understanding, tolerance and respect" (ibidem).

The total number of students included in the study was 293 - 91 Poles, the same number of Ukrainians and 101 Belarusians. Women constitute the majority of subjects $-97.8 \%$ of Poles, $85.7 \%$ of Ukrainians and $78,6 \%$ of Belarusians. All the participants were full-time students. The average age of the Polish students (23.7 years) is slightly higher than the Belarusians (22.5 years) and the Ukrainians (21.7 years). A more differentiating factor is the place of residence. The majority of Polish subjects declare to live in rural areas (59.3\%), whereas $40.7 \%$ claim to live in cities. The values are different for the Ukrainians, $72.5 \%$ of whom declare to live in cities and $27.5 \%$ in the countryside. $52.5 \%$ of the Belarusians, in turn, say that they live in urban areas and $47.5 \%$ in the countryside. Even greater differences between these groups appear when we consider the number of people who stay in touch with somebody from abroad, which was confirmed by $40.7 \%$ of Poles, $86.8 \%$ of Ukrainians and only $26.3 \%$ of Belarusians.

\section{RESULTS AND ANALYSIS}

The collected material was analyzed using the ANOVA method, which investigates the influence of various factors (independent variables) on a dependent variable. The statistically significant cases are then examined to find differences between pairs. In the case of our study, LSD test was employed for that purpose.

Firstly, the relationship between each aspect of cultural sensitivity and the nationalities of the subjects was investigated (Tab. 1). It was established that the nationalities differentiate in a statistically significant way $(\mathrm{p}<0.05)$ four out of five analyzed dimensions, namely Interaction Engagement $(\mathrm{p}=0.003)$, Respect for Cultural Differences ( $\mathrm{p}=0.000)$, Interaction Confidence $(\mathrm{p}=0.000)$ and Interaction Enjoyment $(\mathrm{p}=0.000)$. 
Table 1. Cultural sensitivity and the nationalities of the subjects - ANOVA

\begin{tabular}{|l|c|c|}
\hline \multirow{2}{*}{\multicolumn{1}{|c|}{ Dimensions }} & \multicolumn{2}{c|}{ ANOVA Level } \\
\cline { 2 - 3 } & $\mathrm{F}$ & LSD \\
\hline Interaction Engagement & 3.368 & $\mathbf{0 . 0 0 3}$ \\
\hline Respect for Cultural Differences & 9.665 & $\mathbf{0 . 0 0 0}$ \\
\hline Interaction Confidence & 46.829 & $\mathbf{0 . 0 0 0}$ \\
\hline Interaction Enjoyment & 11.567 & $\mathbf{0 . 0 0 0}$ \\
\hline Interaction Attentiveness & 1.787 & 0.169 \\
\hline
\end{tabular}

$p<0,05$ statistical significance level

The analysis of the first dimension, Interaction Engagement, showed that the most differentiating inter-group variable are the Ukrainian subjects (Tab. 2, Diag. 1). This group got the average result for the analyzed dimension significantly different from the result of the Belarusians $(\mathrm{p}=0.017)$ and close to significant in the case of the Poles $(p=0.064)$.

Table 2. Interaction Engagement and the nationalities of the subjects

\begin{tabular}{|c|c|c|c|c|c|c|c|c|c|c|}
\hline \multirow{2}{*}{\multicolumn{3}{|c|}{ Dependent variable }} & \multicolumn{8}{|c|}{ Grouping variable } \\
\hline & & & \multicolumn{8}{|c|}{ Nationality } \\
\hline \multirow{8}{*}{ 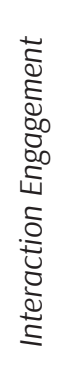 } & \multirow{4}{*}{\multicolumn{2}{|c|}{$\begin{array}{l}\text { ANOVA } \\
\text { Variance } \\
\text { analysis* }\end{array}$}} & \multicolumn{2}{|c|}{ Total } & \multicolumn{2}{|c|}{$U(1)$} & \multicolumn{2}{|c|}{$P(2)$} & \multirow{2}{*}{\begin{tabular}{|c|} 
B (3) \\
\end{tabular}} & \multirow[b]{2}{*}{ SD } \\
\hline & & & $x$ & SD & $x$ & SD & $x$ & SD & & \\
\hline & & & 24.294 & 3.29 & 23.451 & 2.36 & 24.407 & 3.49 & 25.025 & 4.04 \\
\hline & & & \multirow{2}{*}{\multicolumn{2}{|c|}{ Group }} & \multicolumn{6}{|c|}{ Intra-group comparison } \\
\hline & $\mathrm{F}$ & $\mathrm{p}$ & & & \multicolumn{2}{|c|}{ U (1) } & \multicolumn{2}{|c|}{$\mathrm{P}(2)$} & \multicolumn{2}{|c|}{ B (3) } \\
\hline & \multirow{3}{*}{3.368} & \multirow{3}{*}{0.036} & \multicolumn{2}{|c|}{$U(1)$} & & & \multicolumn{2}{|c|}{0.064} & \multicolumn{2}{|c|}{0.017} \\
\hline & & & \multicolumn{2}{|c|}{$P(2)$} & \multicolumn{2}{|c|}{0.064} & & & \multicolumn{2}{|c|}{0.348} \\
\hline & & & \multicolumn{2}{|c|}{ B (3) } & \multicolumn{2}{|c|}{0.017} & \multicolumn{2}{|c|}{0.348} & & \\
\hline
\end{tabular}

*The level is close to significance when $1<p<.05$; significance level when $p<.05$

The results of all the analyzed groups were average. The lowest score was obtained by the Ukrainians (23.451) and the highest by the Belarusians (25.025). The results of the Poles are located between the two. As we can see, the Ukrainians enjoy cultural differences the least and, in consequence, they do not engage in interactions with foreigners. If such interactions do occur, however, they try to behave relatively well towards their cultural counterpart. 


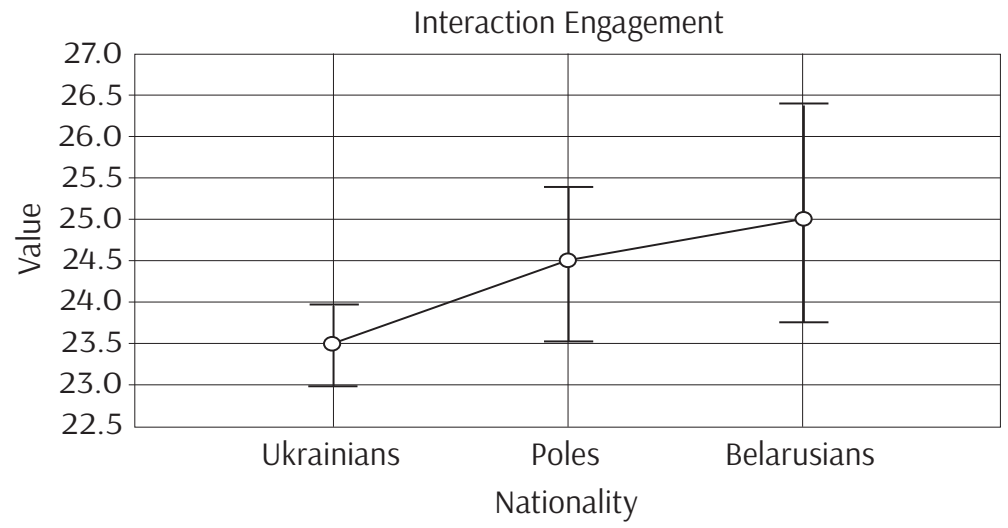

Diagram 1. Interaction Engagement and the nationalities of the subjects (average results 15-28)

Similar situation can be found in the case of the Respect for Cultural Differences dimension. The most diversifying group here are also the students from Ukraine (Tab. 3, Diag. 2). Their average result differs significantly from the scores of the Poles $(p=0.000)$ and the Belarusians $(p=0.048)$. But, unlike the previous case, it is placed in the range of high values (24.308), whereas the others in the range of the average, with the Belarusians reaching the top of this range.

Table 3. Respect for Cultural Differences and the nationalities of the subjects

\begin{tabular}{|c|c|c|c|c|c|c|c|c|c|c|}
\hline \multirow{2}{*}{\multicolumn{3}{|c|}{ Dependent variable }} & \multicolumn{8}{|c|}{ Grouping variable } \\
\hline & & & \multicolumn{8}{|c|}{ Nationality } \\
\hline \multirow{8}{*}{ 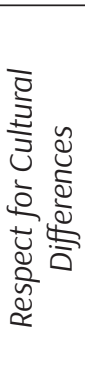 } & \multirow{4}{*}{\multicolumn{2}{|c|}{$\begin{array}{l}\text { ANOVA } \\
\text { Variance } \\
\text { analysis* }\end{array}$}} & \multicolumn{2}{|c|}{ Total } & \multicolumn{2}{|c|}{$U(1)$} & \multicolumn{2}{|c|}{$P(2)$} & \multirow{2}{*}{$\frac{B(3)}{X}$} & \multirow[b]{2}{*}{ SD } \\
\hline & & & $x$ & SD & $x$ & SD & $x$ & SD & & \\
\hline & & & 23.053 & 3.54 & 24.308 & 2.95 & 21.923 & 4.34 & 22.925 & 3.34 \\
\hline & & & \multirow{2}{*}{\multicolumn{2}{|c|}{ Group }} & \multicolumn{6}{|c|}{ Intra-group comparison } \\
\hline & $\mathrm{F}$ & $\mathrm{p}$ & & & \multicolumn{2}{|c|}{$U(1)$} & \multicolumn{2}{|c|}{$P(2)$} & \multicolumn{2}{|c|}{ B (3) } \\
\hline & \multirow{3}{*}{9.995} & \multirow{3}{*}{0.000} & \multicolumn{2}{|c|}{$U(1)$} & & & \multicolumn{2}{|c|}{0.000} & \multicolumn{2}{|c|}{0.048} \\
\hline & & & \multicolumn{2}{|c|}{$P(2)$} & \multicolumn{2}{|c|}{0.000} & & & \multicolumn{2}{|c|}{0.151} \\
\hline & & & \multicolumn{2}{|c|}{ B (3) } & \multicolumn{2}{|c|}{0.048} & \multicolumn{2}{|c|}{0.151} & & \\
\hline
\end{tabular}

*The level is close to significance when $1<p<.05$; significance level when $p<.05$ 


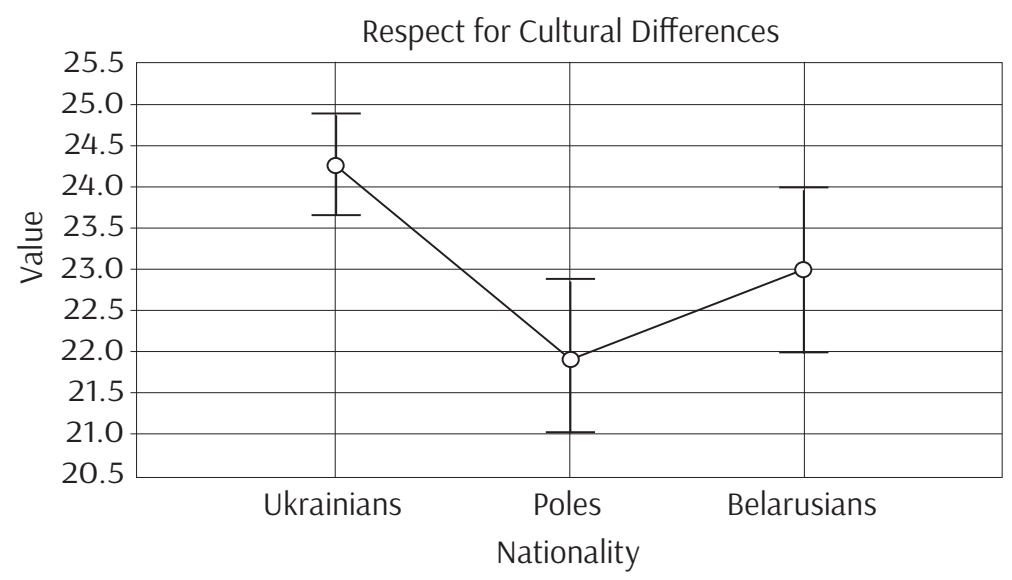

Diagram 2. Respect for Cultural Differences and the nationalities of the subjects (average/high results 15-28)

Such outcomes may point to the fact that the students from Ukraine display much greater level of respect towards cultural differences than their Polish and Belarusian peers. It is expressed mostly by the respect for alternative values and ways of behavior as well as the acceptance of the opinions of others.

The results are slightly different for the analysis of the Interaction Confidence dimension (Tab. 4, Diag. 3). The scores of all the groups can be placed in the range of average values. They differentiate all the groups on statistically significant level $(\mathrm{p}=0.000)$.

Table 4. Interaction Confidence and the nationalities of the subjects

\begin{tabular}{|c|c|c|c|c|c|c|c|c|c|c|}
\hline \multirow{2}{*}{\multicolumn{3}{|c|}{ Dependent variable }} & \multicolumn{8}{|c|}{ Grouping variable } \\
\hline & & & \multicolumn{8}{|c|}{ Nationality } \\
\hline \multirow{8}{*}{ 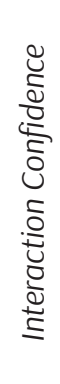 } & \multirow{4}{*}{\multicolumn{2}{|c|}{$\begin{array}{l}\text { ANOVA } \\
\text { Variance } \\
\text { analysis* }\end{array}$}} & \multicolumn{2}{|c|}{ Total } & \multicolumn{2}{|c|}{$U(1)$} & \multicolumn{2}{|c|}{$P(2)$} & \multicolumn{2}{|c|}{$\mathrm{B}(3)$} \\
\hline & & & $x$ & SD & $x$ & SD & $x$ & SD & $x$ & SD \\
\hline & & & 16.34 & 2.81 & 18.396 & 2.53 & 14.396 & 2.95 & 16.225 & 2.95 \\
\hline & & & \multirow{2}{*}{\multicolumn{2}{|c|}{ Group }} & \multicolumn{6}{|c|}{ Intra-group comparison } \\
\hline & $\mathrm{F}$ & $p$ & & & \multicolumn{2}{|c|}{$U(1)$} & \multicolumn{2}{|c|}{$P(2)$} & \multicolumn{2}{|c|}{$\mathrm{B}(3)$} \\
\hline & & & \multicolumn{2}{|c|}{$U(1)$} & & & \multicolumn{2}{|c|}{0.000} & \multicolumn{2}{|c|}{0.000} \\
\hline & 46.829 & 0.000 & \multicolumn{2}{|c|}{$P(2)$} & \multicolumn{2}{|c|}{0.000} & & & \multicolumn{2}{|c|}{0.000} \\
\hline & & & \multicolumn{2}{|c|}{ B (3) } & \multicolumn{2}{|c|}{0.000} & \multicolumn{2}{|c|}{0.000} & & \\
\hline
\end{tabular}

*The level is close to significance when $1<p<.05$; significance level when $p<.05$ 


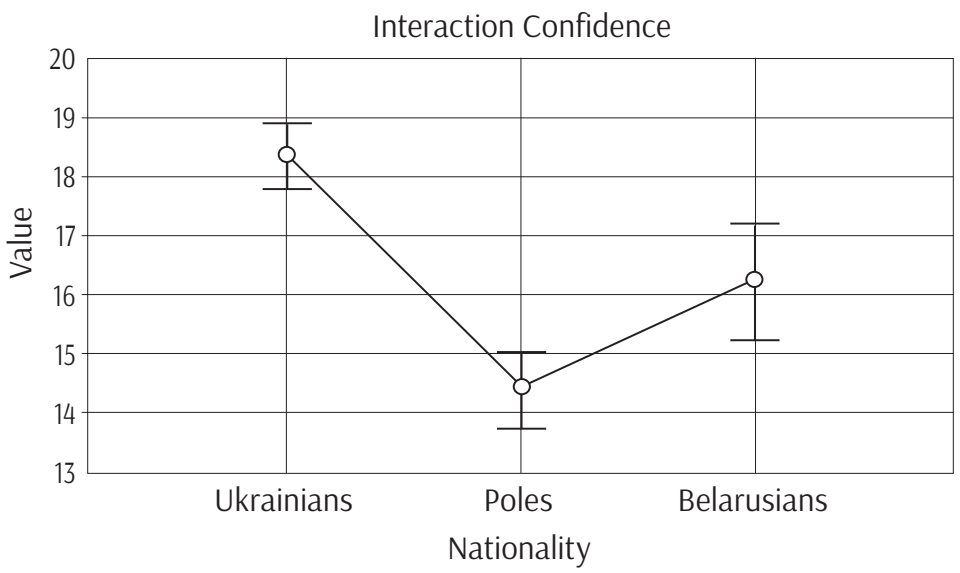

Diagram 3. Interaction Confidence and the nationalities of the subjects (average results 11-29)

The result the closest to the high range was obtained by the students from Ukraine (18.396), the second closest belongs to the Belarusians (16.225) and the third one to the Poles (14.396). Such outcomes make it possible to generalize that the Ukrainians present the greatest confidence in interactions with the people of different culture. It is mainly expressed by their self-confidence and sociability in such situations.

The analysis of the last dimension, namely Interaction Enjoyment, similarly to the previous ones, points at the Ukrainians as the most diversifying group (Tab. 5, Diag. 4). Their average result is significantly different from the ones achieved by the Poles $(p=0.000)$ and the Belarusians $(p=0.017)$. What is more, it is located in the high range of results, whereas the others in the average. The Belarusians (10.925), however, show tendency towards the high range and the Poles achieved the lowest average score.

It can be assumed that the Ukrainian subjects present the highest (high) level of interaction enjoyment among the analyzed groups. They do not get angry when faced with the need to communicate with foreign people. They show their satisfaction with the situations, at the same time feeling needed. 
Table 5. Interaction Enjoyment and the nationalities of the subjects

\begin{tabular}{|c|c|c|c|c|c|c|c|c|c|c|}
\hline \multirow{2}{*}{\multicolumn{3}{|c|}{ Dependent variable }} & \multicolumn{8}{|c|}{ Grouping variable } \\
\hline & & & \multicolumn{8}{|c|}{ Nationality } \\
\hline \multirow{8}{*}{ 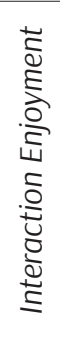 } & \multirow{4}{*}{\multicolumn{2}{|c|}{$\begin{array}{l}\text { ANOVA } \\
\text { Variance } \\
\text { analysis* }\end{array}$}} & \multicolumn{2}{|c|}{ Total } & \multicolumn{2}{|c|}{ U (1) } & \multicolumn{2}{|c|}{$P(2)$} & \multicolumn{2}{|c|}{ B (3) } \\
\hline & & & $x$ & SD & $x$ & SD & $X$ & SD & $x$ & SD \\
\hline & & & 11.055 & 2.03 & 11.824 & 1.77 & 10.418 & 2.06 & 10.925 & 2.26 \\
\hline & & & \multirow{2}{*}{\multicolumn{2}{|c|}{ Group }} & \multicolumn{6}{|c|}{ Intra-group comparison } \\
\hline & $\mathrm{F}$ & p & & & \multicolumn{2}{|c|}{$U(1)$} & \multicolumn{2}{|c|}{$\mathrm{P}(2)$} & \multicolumn{2}{|c|}{$\mathrm{B}(3)$} \\
\hline & \multirow{3}{*}{11.567} & \multirow{3}{*}{0.000} & \multicolumn{2}{|c|}{ U (1) } & & & \multicolumn{2}{|c|}{0.000} & \multicolumn{2}{|c|}{0.017} \\
\hline & & & \multicolumn{2}{|c|}{$\mathrm{P}(2)$} & \multicolumn{2}{|c|}{0.000} & & & \multicolumn{2}{|c|}{0.179} \\
\hline & & & \multicolumn{2}{|c|}{ B (3) } & \multicolumn{2}{|c|}{0.017} & \multicolumn{2}{|c|}{0.179} & & \\
\hline
\end{tabular}

*The level is close to significance when $1<p<.05$; significance level when $p<.05$

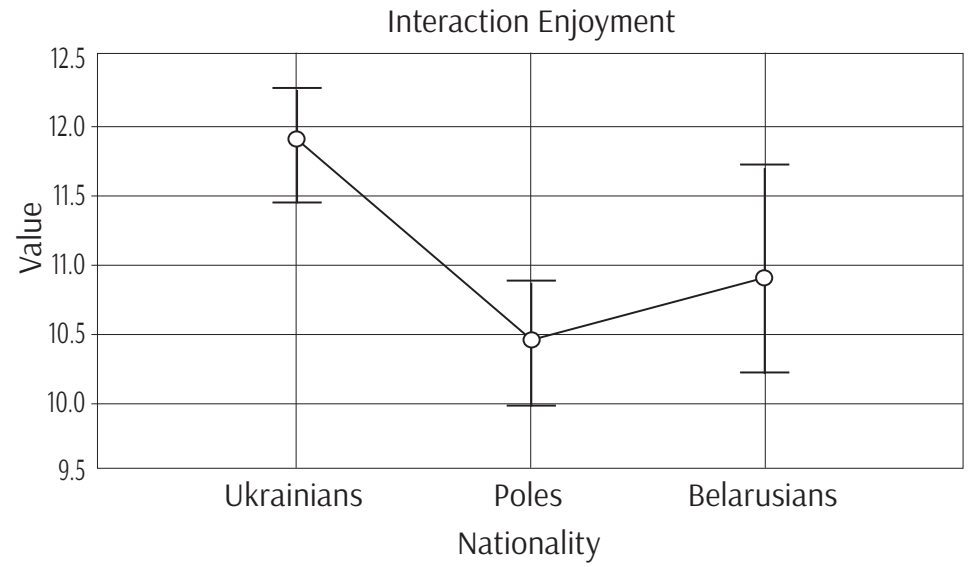

Diagram 4. Interaction Enjoyment and the nationalities of the subjects (average/high results)

The validity of the above analyses of individual dimensions is confirmed by the examination of the global result pertaining to cultural sensitivity in the context of the nationalities of the subjects. First of all, such analysis showed that this factor significantly differentiates the global results (Tab. 6).

Table 6. The global result of "Cultural sensitivity" of the subjects in the context of their nationalities - ANOVA

\begin{tabular}{|c|c|c|}
\hline \multirow{2}{*}{ Global result } & \multicolumn{2}{|c|}{ ANOVA level } \\
\cline { 2 - 3 } & $\mathrm{F}$ & LSD \\
\hline "Cultural sensitivity" & 11.985 & 0.000 \\
\hline
\end{tabular}

significance level when $p<.05$ 
Another analysis by means of the LSD test showed that the Ukrainians are the statistically significant diversifying group (Tab. 7, Diag. 5). Their global result of 88.659 is significantly different $(p=0.000)$ from the global result of the Poles (81.747) and is close to statistical significance $(\mathrm{p}=0.055)$ for the result of the Belarusians (85.175). The difference between the latter two groups is also close to significant $(\mathrm{p}=0.059)$. All the results are located in the range of average values.

Table 7. The global result of "Cultural sensitivity" of the subjects in the context of their nationalities - LSD

\begin{tabular}{|c|c|c|c|c|c|c|c|c|c|c|}
\hline \multirow{2}{*}{\multicolumn{3}{|c|}{ Dependent variable }} & \multicolumn{8}{|c|}{ Grouping variable } \\
\hline & & & \multicolumn{8}{|c|}{ Nationality } \\
\hline \multirow{8}{*}{ 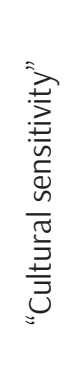 } & \multirow{4}{*}{\multicolumn{2}{|c|}{$\begin{array}{l}\text { ANOVA } \\
\text { Variance } \\
\text { analysis* }\end{array}$}} & \multicolumn{2}{|c|}{ Total } & \multicolumn{2}{|c|}{$U(1)$} & \multicolumn{2}{|c|}{$P(2)$} & \multicolumn{2}{|c|}{$\mathrm{B}(3)$} \\
\hline & & & $x$ & SD & $x$ & SD & $x$ & SD & $x$ & SD \\
\hline & & & 11.055 & 2.03 & 88.659 & 1.77 & 81.747 & 2.06 & 85.175 & 2.26 \\
\hline & & & \multirow{2}{*}{\multicolumn{2}{|c|}{ Group }} & \multicolumn{6}{|c|}{ Intra-group comparison } \\
\hline & $\mathrm{F}$ & $\mathrm{p}$ & & & \multicolumn{2}{|c|}{$U(1)$} & \multicolumn{2}{|c|}{$\mathrm{P}(2)$} & \multicolumn{2}{|c|}{$B(3)$} \\
\hline & \multirow{3}{*}{11.985} & \multirow{3}{*}{0.000} & \multicolumn{2}{|c|}{$U(1)$} & & & \multicolumn{2}{|c|}{0.000} & \multicolumn{2}{|c|}{0.055} \\
\hline & & & \multicolumn{2}{|c|}{$\mathrm{P}(2)$} & \multicolumn{2}{|c|}{0.000} & & & \multicolumn{2}{|c|}{0.059} \\
\hline & & & \multicolumn{2}{|c|}{ B (3) } & \multicolumn{2}{|c|}{0.055} & \multicolumn{2}{|c|}{0.059} & & \\
\hline
\end{tabular}

*The level is close to significance when $1<p<.05$; significance level when $p<.05$

Global Results

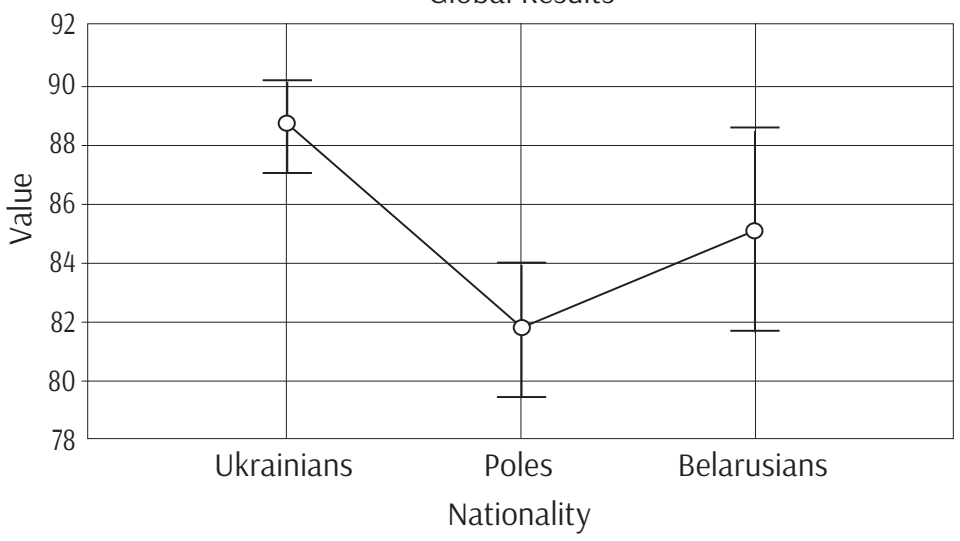

Diagram 5. The global result of "Cultural sensitivity" of the subjects in the context of their nationalities (average results 49-95) 
Taking all the above analyses into consideration, it can be concluded that the Ukrainians present the highest willingness to engage in interactions with people of different cultures.

\section{CONCLUSIONS}

The analyses presented above seem to corroborate the initial hypothesis. It turned out that the students from Ukraine obtained the highest results for all the dimensions except the first one, Interaction Engagement. Two of these scores, namely Interaction Enjoyment and Respect for Cultural Differences, are located in the high range of values, the other two are average. The global result of this group was also the highest. The Belarusians obtained lower results, which were, however, always higher than the ones of the Poles. All the values were average, but two of them (Interaction Enjoyment and Respect for Cultural Differences) were close to the high range. The lowest results, both with respect to individual dimensions and global, belong to the Polish students and their values are all in the average range.

Generally speaking, it can be concluded that the subjects of the study, irrespectively of their nationality, are generally cautious when interacting with people of foreign cultures. They are not very open and do not express happiness with interactions but are rather afraid of them. When interactions do occur, only the Ukrainian subjects are able to show respect and appreciation of other cultures without expressing the superiority of their own. Also, much more frequently than the Poles and the Belarusians, they know what to say in a conversation. They are sociable and friendly, which allows them to derive pleasure from interactions with foreigners. They are calm and pleased but also feel needed and useful. Occasionally, however, they may not be very attentive and sensitive to the subtleties of the messages.

The conducted analyses also allow to assess the level of cultural sensitivity of the Polish subjects. The conclusions that can be drawn are that they are not very open-minded and do not enjoy direct contact with foreigners. During interaction, they keep their distance, showing average level of understanding, which is expressed by their verbal and non-verbal behavior. They are not confident in communicative situations as they believe that it is difficult to get their messages across. As a result, they are not pleased when interactions appear. They do not pay attention and realize them only superficially, showing no interest in the richness and subtlety of the contents. They do not always respect and accept different values and ways of behavior, believing that their own culture is better than the other. 
Unfortunately, such picture is not very positive. Naturally, in many cases it may be unfair and detrimental. In order for it to be more reliable, further studies involving greater number of subjects should be conducted. A constructive debate of the problem is also problematic due to the lack of similar studies. However, when compared with the outcomes of similar pieces of research, for instance, the study of social distance towards foreigners (Bera \& Korczyński, 2012), our results seem rather accurate, properly reflecting the present reality in which xenophobic phenomena are becoming increasingly common.

But it needs to be remembered that the increasing mobility of societies, the ability to travel quickly combined with the access to modern means of communication make intercultural contacts a common phenomenon. Frequent migrations, also for educational purposes, cause different cultures to meet and mix. In the globalized world, the possession and development of intercultural skills is a must (Matsumoto \& Juang, 2007). Such skills can be developed thanks to the process of learning new cultures, identifying differences between them, noticing alternative perspectives on the same ideas and dealing with different conceptions of reality.

The research point to the need of intensifying intercultural education, the beginnings of which should take place at home, where a young person should acquire open-minded attitude and willingness to engage in interactions with people of different cultures. The church should assist parents in this task. These values should also be present in the process of formal education at all levels (kindergarten, primary schools, vocational schools, high schools and universities). The curricula of all subjects should contain outcomes connected with cultural education. The topics connected with it could be discussed as a separate subject or as a component of the already existing ones. The final stage is continuous, life-long, informal education realized by the television and the Internet.

\section{References}

Bennett, M.J. (1993). Towards Ethnorelativism: A Development Model of Intercultural Sensitivity. In: R.M. Paige (Ed.), Education for the Intercultural Experience (pp. 21-71). 2nd Ed. Yarmouth, EM: Intercultural Press.

Bera, R., \& Korczyński, M. (2012). Dystans społeczny polskich emigrantów wobec "obcych” $i$ "innych". Lublin: UMCS.

Chen, G.M., \& Starosta, W.J. (1997). A Review of the Concept of Intercultural Sensitivity. Human Communication, 1 (1), pp. 1-16. Retrieved from: https://files.eric.ed.gov/fulltext/ ED408634.pdf.

Cieślikowska, D. (2006). Problemy integracji osób odmiennych kulturowo. In: A. Paszkowska-Rogacz, E. Olczak, E. Kownacka, \& D. Cieślikowska, Doradztwo zawodowe a wyzwania międzykulturowe (pp. 65-90). Warszawa: KOWEZiU. 
Fritz, W., Mollenberg, A., \& Chen, G.M. (2002). Measuring Intercultural Sensitivity in Different Cultural Contexts. Intercultural Communication Studies, 11 (2), pp. 165-176. Retrieved from: http://digitalcommons.uri.edu/com_facpubs/29 (accessed: 10.10.2017).

Fritz, W., Graf, A., Hentze, J., Mollenberg, A., \& Chen, G.M. (2005). An Examination of Chen and Starosta's Model of Intercultural Sensitivity in Germany and United States. Intercultural Communication Studies, 14 (1), pp. 53-64. Retrieved from: http://digitalcommons. uri.edu/com_facpubs (accessed: 12.08.2017).

Konecki, K.T., \& Chomczyński, P. (2012). Słownik socjologii jakościowej. Warszawa: Difin.

Korczyński, M., \& Świdzińska, A. (2017). Wrażliwość międzykulturowa studentów z pogranicza polsko-ukraińskiego. Edukacja Międzykulturowa, 1 (6), pp. 113-129.

Matsumoto, D., \& Juang, L. (2007). Psychologia międzykulturowa. Gdańsk: GWP.

Nikitorowicz, J. (2014). Wielokulturowość - Pogranicze - Człowiek pogranicza. Ku paradygmatowi współistnienia, zachowania i kreowania pokoju. Drohiczyński Przegląd Naukowy: Wielokulturowe Studia Drohiczyńskiego Towarzystwa Naukowego, 6, pp. 171-189.

Nikitorowicz, J., Sobecki, M., Danilewicz, W., Muszyńska, J., Misiejuk, D., \& Bajkowski, T. (2013). Kompetencje do komunikacji międzykulturowej w aspekcie wielokulturowości regionów i procesów migracyjnych. Warszawa: Wydawnictwo Akademickie Żak.

Reber, A. (2000). Słownik psychologii. Warszawa: Wydawnictwo Naukowe SCHOLAR.

Siwińska, B. (Ed.) (2017). Studenci zagraniczni w Polsce 2017. Report of "Perspektywy” Education Foundation.

Śliwerski, B. (2015). Współczesne teorie i nurty wychowania. 9th Ed. Kraków: Wydawnictwo Uniwersytetu Jagiellońskiego. 